\title{
Brake by wire control with pedal feedback and brake boost
}

\author{
W. A. Shanaka P. Abeysiriwardhana, A. M. Harsha S. Abeykoon \\ Department of Electrical Engineering, Faculty of Engineering, University of Moratuwa, Katubedda, Sri Lanka
}

\begin{tabular}{l} 
Article Info \\
\hline Article history: \\
Received Nov 9, 2020 \\
Revised Mar 2, 2021 \\
Accepted Oct 9, 2021 \\
\hline
\end{tabular}

\section{Keywords:}

Bilateral teleoperation

Brake by wire

Pedal feel

Reaction force observer

\begin{abstract}
"By wire" technology merged into multiple vehicular subsystems, including gear changing, drive, and braking systems. The brake by wire system is developed to overcome the problems associated with the integration of mechanical and hydraulic systems in novel vehicular systems. Even though brake by wire systems has potential advantages, the conventional brake systems' tactile sensation will be removed if migrated to the electrical by wire control scheme. This paper proposes a novel control mechanism that provides amplification of force, scaling of position replication, and a virtual springdamper based pedal retraction which provides bilateral brake force feedback to the driver's pedal similar to the hydraulic brake system. The proposed system performance was simulated and tested using a bilateral teleoperation system with disturbance observers (DOB) and reaction force observers (RFOB). The proposed system provides pedal force amplification and brake force feedback to the driver's pedal using RFOBs. The virtual spring retracts the brake pedal, similar to a mechanical pedal retraction system. The system simulation and experimental results provide evidence of the proposed system's force amplification, position scaling, and pedal reaction capabilities.
\end{abstract}

This is an open access article under the CC BY-SA license.

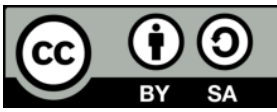

\section{Corresponding Author:}

W. A. Shanaka P. Abeysiriwardhana

Department of Electrical Engineering, Faculty of Engineering

The University of Moratuwa

Katubedda, Sri Lanka

Email: shanaka@elect.mrt.ac.lk

\section{INTRODUCTION}

Land transportation is one of the significant transport methods that support human day to day life. Land transport systems mainly consist of automobile and rail transport systems. Proper acceleration, deceleration, and direction control provide for the safe operation of these systems. Vehicular systems are gradually transferring towards electrical subsystems due to financial and technical factors. The use of fossil fuels is discouraged due to financial and environmental factors. Technically, electrical systems are said to be reliable than mechanical systems [1]. Vehicular systems now integrate complex control systems with electrical actuators and sensor networks to improve vehicular performance and ride quality [2]-[4]. Improving the brake system is, therefore, an integral part of upgrading the total vehicle control system.

The brake system is considered to be an essential subsystem that prevents accidents. Therefore, braking system reliability and sensitivity are crucial for road safety [5]. Hydraulic and mechanical brake systems are the first brakes that were introduced to vehicles. In 1902 French manufacturer Louis Renault developed the first drum brakes to be used in modern vehicles [6]. Initially, brake systems used mechanical linkages to transfer the driver's braking intention to the wheels. Due to limitations of mechanical linkages, hydraulic systems were later introduced to transfer the force between the pedal and the wheels. Disc brake systems are used in lightweight vehicles, and other safety systems such as anti-lock braking system (ABS) provide additional vehicle safety [7]. 
When braking the pedal is used to exert the intended brake forces to brake pads and the wheel. Human muscle power is used to press the brake pedal, and the force is amplified and transferred to the brake pads by hydraulic pressure distribution mechanisms with the aid of vacuum boosters [8]. The human muscle force is amplified in a conventional hydraulic braking system using the ratio of fluid valve and pressure [9]. In addition, the hydraulic system contains brake boost technologies [10]. The driver receives the feedback of the brake pad force from fluid pressure generated at the pads. After the brake application, the brake pedal retracts to its original position using a mechanical overhang spring, which is placed in between the vehicle body and the pedal.

The conventional hydraulic system suffers from drawbacks associated with the hydraulic force transfer systems [11]. If hydraulic lines are replaced with electrical systems, the reliability could be improved. Brake by wire technology overcame the limitations of the hydraulic system and improved the brake system [12]. The by wire brake systems started to emerge with the emergence of electrical drivers and actuators that support by Wire technology [13].

By wire systems reduce hydraulic and mechanical actuators' usage and linkages in automobiles, improving overall performance [14]. In brake by wire systems, electromechanical actuators actuate brake pads and brake pedal, and an electronic controller controls force transfer. The pedal, brake pad, and tire movements are measured using electronic encoders or resolvers [15]. Electronic controllers transfer and process the information that controls the braking system based on the driver's intention. Electro-mechanical brake (EMB) actuators are developed in [16] to work as conventional brake pads by providing brake friction force to the disc. They proposed the construction of mechanical design and provided brake actuators' performance, but pedal to brake control techniques are yet to be researched. EMBs are proposed to be used as the brake actuators to exert braking force through brake clamps. Information on forces in EMBs are analyzed in [17], expressing the necessary sensor requirements to assess forces and positions of the EMBs.

Additionally, they provide the associated problems with sensing and using the data. The EMB control and sensor availability have been further analyzed in [18], indicating that EMBs would incorporate position sensors, and force sensors. However, brake clamp force estimation may be susceptible to nonlinearities [15]. Control methods published in the above literature do not provide bilateral feedback schemes that incorporate force feedback systems. Bilateral control techniques [19]-[22] are well published for different applications, but the usage for brake by wire systems is limited. A conventional bilateral controller is proposed for brake by wire system in [23]. However, they have not considered the stiffness change experienced when the brake pad is in contact. Electromechanical brakes exhibit multiple challenges if it to be transformed into a "By Wire" system. When brake clamps are in contact motion, force measurement and control are challenging due to noise and hysteresis [15], [24]. EMB caliper control techniques were reviewed that control brake calipers using different control techniques in [25]. EMB caliper control using current, speed, position-based PI control was proposed to drive brake motors by Baek et al. [26]. They propose a traditional PI control method to precisely control the braking forces of the calipers using interior permanent magnet synchronous motors. Even though Baek et al. [26] efficiently operate the brake motor, the force feedback to the driver is not considered.

Similarly, adaptive algorithms were used to improve the estimation error of temperature changes and friction wear [27], improving operation safety and motor efficiency. A double-loop cascade control was proposed to address the non-linearity between the piston positions of hydraulic pressure [28] of the electrohydraulic brake system. However, they only consider the operation of the electrohydraulic brakes without considering the EMBs. EMB brake systems do not get affected by hydraulic fluid effects due to the usage of electromechanical actuators. Furthermore, the observer-based friction force estimation for the brake system was proposed by Qian et al. [29]. The above controllers mainly focus on noise reduction, caliper force control, and non-linearity reduction of the control algorithm. However, even though the previous research improve the performance of caliper force control, they do not consider the pedal feel or pedal retraction experienced by the driver, which is essential for the driver to receive the feedback of the force application. Therefore, a novel brake by wire control system should develop with bilateral feedback technique using available, reliable sensors in EMBs. The system should also provide brake boost and pedal sensation to the driver as a driver's aid while using existing mechanical brake system operation knowledge.

This paper proposes a novel control methodology with force amplification, position scaling, and virtual spring-damper-based force feedback and pedal retraction. The proposed control technique is developed by observing the hydraulic brake system to produce a bilateral control that suits the needs of the EMB based brake by wire system. The brake pedal controller uses a scaled force control loop, and the brake actuator controller uses a position control loop. The brake pedal and brake clamp motors are bilaterally connected with force feedback and the brake actuator's position feedback. The controller uses reaction force observer (RFOB) [30]-[32] based force measurement with current and position sensors to avoid the usage of force sensors in the brake motor, which is prone to noises generated by the brake clamps. Proposed force and position controllers use multiple adaptive regional scalars to generate the brake amplification, position

Brake by wire control with pedal feedback and brake boost (W. A. Shanaka P. Abeysiriwardhana) 
scaling, and pedal retraction. The brake motor uses position control similar to the hydraulic brake system's position replication that automatically compensates for the pedal wear. Pedal position is scaled to match the brake clamp's maximum displacement.

Additionally, adaptive spring damper coefficients are used to prevent over-retraction of the pedal by increasing the virtual spring damping coefficients. The proposed system will provide force amplification, position scaling, virtual spring-damper-based force feedback, and pedal retraction. Separate force control and position control loops are used in the novel implementation that replaces the force-position replicated conventional bilateral control. The pedal movement can be quickly controlled using the human foot movement by removing the force replication in the brake side. Disturbance observer (DOB) [33], [34] was used to improve the position control loop's reaction time under the braking loads. The proposed control technique is similar to a hydraulic brake system where the foot position controls the pedal position, and the axillary actuators support the forces required for the movement.

Additionally, the proposed system assumes brake motor angle and the brake clamp force [24], to provide a consistent brake output. The brake motor force and the brake force measurement show a highly nonlinear relationship, and the non-linearity is avoided by removing the pedal force replication in the brake clamp motor. From the brake motor side, RFOB based scaled force is used as brake feedback to the pedal. The modelled system was designed to be used with direct current (DC) linear or rotary motors. A linearized mathematical model of two DC motors is used for the proposed system's modelling and simulation. The model can be applied for both linear DC or rotary DC motors by changing the motor parameter values. The vehicle brake pedal is retracted through a virtual spring. The pedal force feedback provides information to the driver about the pedal displacement and brake force. The system is simulated in MATLAB Simulink [35]. The experimental results were later gathered with a bilateral teleoperation experimental setup. The mathematical modelling of the proposed system is explained in section 2. The evaluation of the system through simulation and experiments are provided in section 3. Finally, the paper is concluded in section 4.

\section{RESEARCH METHOD}

Conventional hydraulic brakes use hydraulic fluid and assisting technologies to operate the pedal and pads bilaterally, as shown in Figure 1. The modelled brake by wire controller transfers the pedal force to the pads using electronic signals where the motor sensors observe the brake force and the position. The proposed method uses a mechanical brake system as a reference to create similar feedback in the drivers pedal. Scaled brake force is fed back to the brake pedal actuator to provide brake application feedback to the driver.

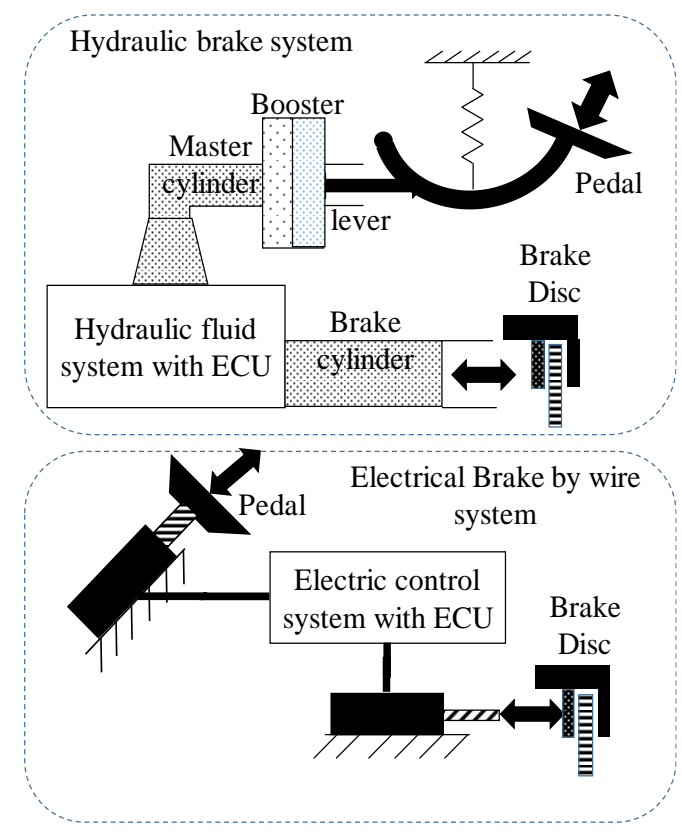

Figure 1. Mechanical and by wire brake systems 
Additionally, a virtual spring and a damper in the pedal controller allow the brake pedal's retraction. The brake motor runs in a position control loop, and the scaled pedal position is used as the brake motor reference, Similar to a conventional hydraulic system. Figure 2 (a) shows the simulated brake model with force and position directions, two DC motors used in the system simulation, and experiments. The caliper force depending on the brake movement is shown in Figure 2 (b).

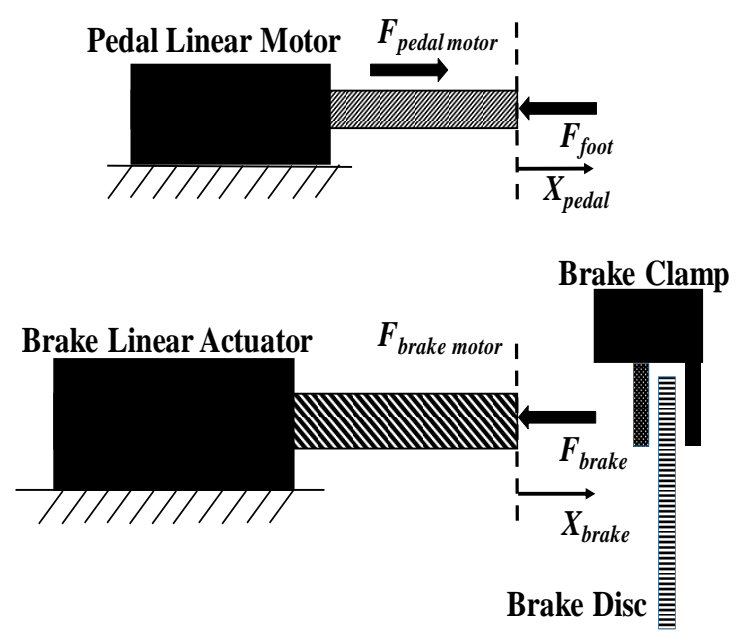

(a)

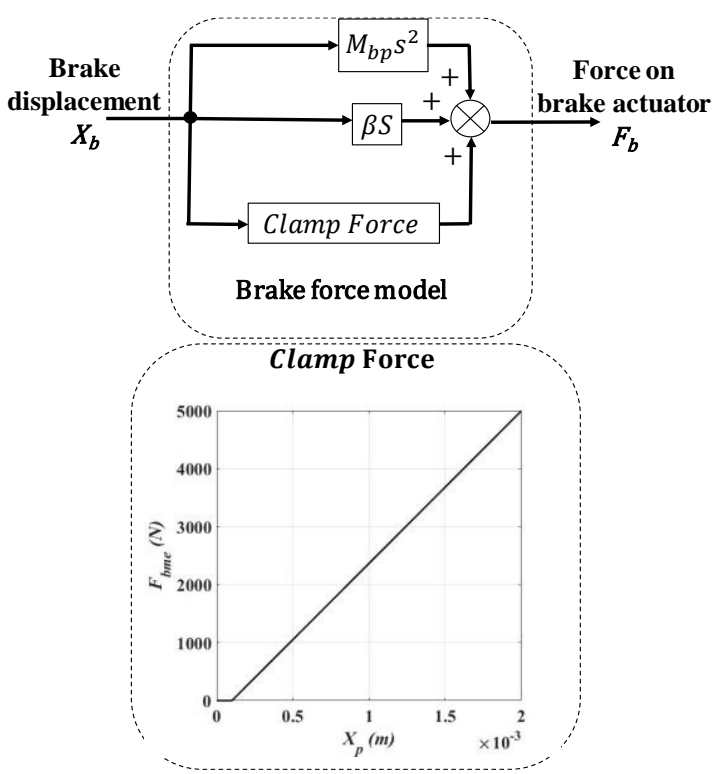

(b)

Figure 2. Simulated system motor forces; (a) motor force-position directions, (b) clamp force model

In the hydraulic system, the pedal force pushes a rod that activates the vacuum brake booster [8]. For modelling, it was approximated that the vacuum boost force is proportional to brake pedal force because the amount of pressure difference depends on the amount of air escaped from the vacuum chamber, which depends on the amount of brake applied. Therefore, the brake booster assist force approximation is given in $(1)$, where $F_{\text {boost }}$ is the brake booster assist force, $K_{\text {boost }}$ is the brake boosting constant, and $F_{\text {pedallever }}$ Force is applied on the master cylinder by the pedal lever.

$$
F_{\text {boost }}=K_{\text {boost }} F_{\text {pedallever }}
$$

The pedal lever force depends on the driver's foot force and pedal lever ratio [32]. The pedal lever force can be calculated as in (2) where $R_{\text {pedallever }}$ is the pedal lever ratio, $F_{\text {foot }}$ is the force applied by the driver's foot.

$$
F_{\text {pedallever }}=R_{\text {pedallever }} F_{\text {foot }}
$$

The force applied on the master cylinder in the hydraulic system can be derived as (3) where $F_{\text {pedal }}$ master is master cylinder force generated by pedal side, $F_{\text {spring }}$ is spring force applied on the pedal lever $F_{\text {damp }}$ damping force applied on the pedal lever from friction.

$$
F_{\text {pedal_master }}=F_{\text {boost }}+F_{\text {pedallever }}+F_{\text {spring }}+F_{\text {damp }}
$$

The brake by wire model $K_{\text {boost }}$ is approximated to $K_{\text {boost }}+1$ to incorporate pedal lever and boost forces. The pedal spring and damper forces can be derived as in (4), (5) where $X_{\text {pedallever }}$ is approximate pedal lever moment $K_{\text {spring }}$ is spring coefficient of the pedal, and $C_{\text {damp }}$ is damping coefficient of the pedal.

$$
\begin{aligned}
& F_{\text {spring }}=K_{\text {spring }} X_{\text {pedallever }} \\
& F_{\text {damp }}=C_{\text {damp }} X_{\text {pedallever }} S
\end{aligned}
$$


The force applied on the brake clamp can be calculated as (6), where $F_{\text {brake_clamp }}$ is the force applied on Brake Clamp, $A_{\text {master }}$ is the area of the master cylinder and $A_{\text {brake }}$ brake cylinder. The ratio between the master cylinder and brake cylinder is considered to be $A_{\text {ratio }}$

$$
F_{\text {brake_clamp }}=F_{\text {master }} \frac{A_{\text {master }}}{A_{\text {brake }}}
$$

This can be converted into a position relationship as in (7), assuming that the ideal liquid is used in the master cylinder.

$$
X_{\text {brake_clamp }}=X_{\text {master }} \frac{A_{\text {brake }}}{A_{\text {master }}}
$$

In the brake by wire model, the force transfer mechanism is converted using the DC motors. The master cylinder and brake cylinder is converted into DC motors. We could derive Newton's equations for pedal and brake motors as (8), $(9), F_{\text {pedalmotor }}$ is reaction force excreted by the pedal motor, $F_{\text {brake }}$ motor is the force exerted on the brake motor by the pads, $F_{\text {brake }}$ motor is the brake motor force, and $F_{\text {brake }}$ is the brake force applied on the motor.

$$
\begin{aligned}
& F_{\text {pedalmotor }}+F_{\text {pedallever }}=M_{\text {pedal }} X_{\text {pedallever }} S^{2} \\
& F_{\text {brakemotor }}+F_{\text {brake }}=M_{\text {brake }} X_{\text {brake }} S^{2}
\end{aligned}
$$

Using the pedal motor data and (7), the force on the brake motor can be calculated similarly to the mechanical system (10) where $K_{P b}, K_{I b}$, and $K_{D b}$ are PID coefficients of brake motor position controller. The pedal motor position was taken for brake motor reference considering the noise filtration and approximations taken into the pedal RFOB. Using the position reference from encoders are more reliable and not prone to EMI as current sensors.

$$
F_{\text {brakemotor }}=\left(K_{p b}+K_{i b} s+\frac{K_{D b}}{s}\right)\left(\frac{X_{\text {pedallever }}}{A_{\text {ratio }}}-X_{\text {brake }}\right)
$$

The $F_{\text {pedal }}$ motor can be calculated using (10) as (11).

$$
F_{\text {pedalmotor }}=\frac{F_{\text {brake }}}{K_{\text {boost }} A_{\text {ratio }}}+F_{\text {spring }}+F_{\text {damp }}
$$

The motor forces and positions are then applied to the motor using the current controller. The reaction forces of the brake motor are measured using RFOB, as shown in Figure 3 (a). The force can be calculated using (12), where $I_{a}$ is the brake motor current and $K_{f b}$ motor constant of the brake.

$$
F_{\text {brakemotor }}=I_{a} K_{f b}
$$

The brake motor position can be calculated using (13), where $M_{b}$ is the brake motor weight, and $X_{b}$ is the brake motor position.

$$
X_{b}=\frac{F_{\text {brakemotor }}-F_{\text {brake }}}{M_{b} s^{2}}
$$

The brake force can be calculated with RFOB using (14), where $K_{f b n}$ is the nominal brake motor constant, $M_{b n}$ is the nominal brake motor weight, and $G$ is the low pass filter constant used for noise reduction.

$$
F_{R F O B}=\left(M_{b n} X_{b} s^{2}+I_{a} K_{f b}\right)\left(\frac{1}{s+G}\right)-F_{f r i c}
$$

The pedal motor model can be calculated as above. The pedal motor variables are names that contain "p" such that Pedal Motor's constant variable is $K_{f p}$. The saturation of master and slave motors was added to (8) and (9) as $50 \mathrm{~N}$ and $100 \mathrm{~N}$, respectively. In the brake simulation model, the clamp contains linearized clamp force, brake pad acceleration force, and friction forces, as given in (15). The clamping force is considered zero in $0.1 \mathrm{~cm}$ and linearly increases afterwards, as shown in Figure 2 (b). 


$$
F_{\text {brake }}=F_{\text {clampforce }}+\beta s+M_{\text {pad }} X s^{2}
$$

The proposed controller can provide brake retraction capability, brake amplification, and brake feedback to the driver. The system consists of a master motor and a slave motor, as shown in Figure 3 (b). The regional position scaling constants are used in the system to allow quick brake motor movement until it reaches the brake pad, where RFOB detects reaction force from the brake clamps. Afterwards, the scalar adjusts itself to the regular value providing a smooth brake motor's position variation with the brake application as described in the model.

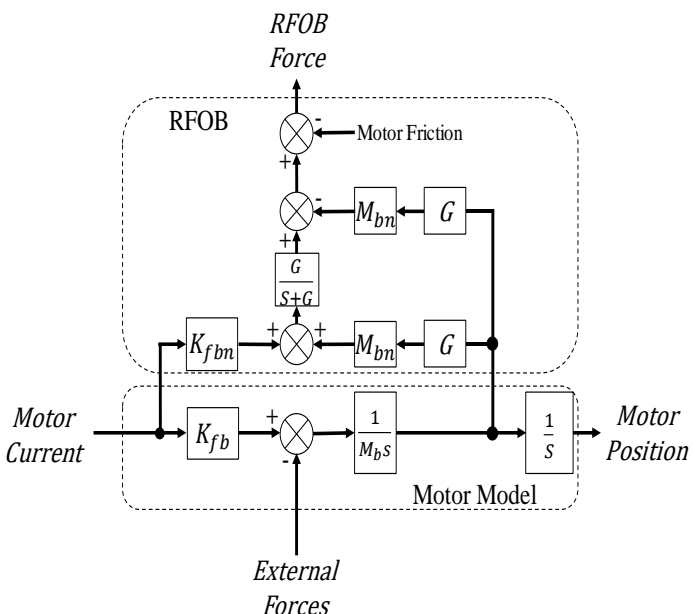

(a)

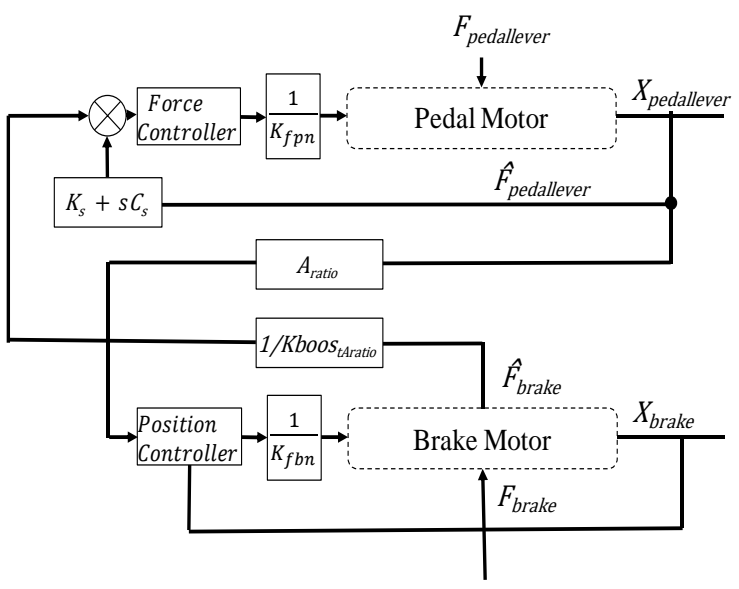

(b)

Figure 3. These figures are; (a) motor model with RFOB, (b) brake by wire controller

\section{RESULTS AND DISCUSSION}

The system was simulated using a linear motors model and validated experimentally with a rotary motor system to show its ability to work with both rotary and linear motors as shown in Figure 4 . The simulation was carried out in a MATLAB Simulink environment. The parameters of linear and rotary motor models are described in Table 1. The clamp forces of EMBs are used as brake model parameters. The brake system frequency response between the pedal force and the brake force is shown in Figure 5 (a). The simulation suggests the force amplification capability of the proposed controller up to $10 \mathrm{~Hz}$, which is on par with the pedal's human response capability. The system stability is further simulated using a pole-zero diagram, as shown in Figure 5 (b). The ten poles and zeros are present on the negative side and no poles on imaginary axis showing any oscillations of the system. The proposed control simulations for frequency and pole-zeros suggest the proposed controller's stability within the interested frequency range.

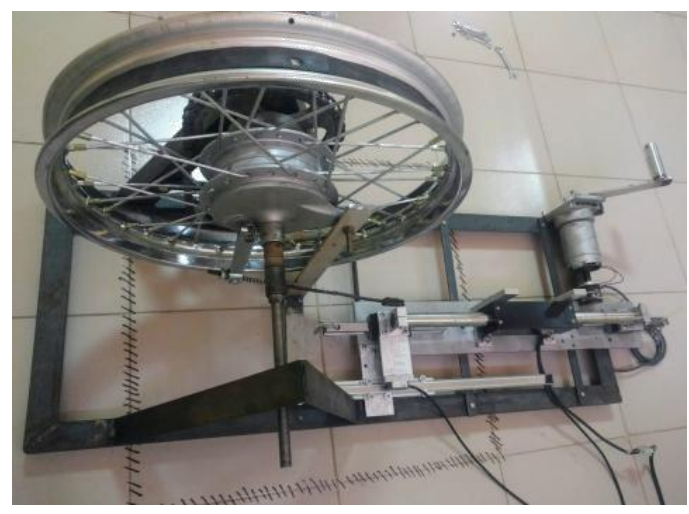

Figure 4. Experimental system
Table 1. System parameters

\begin{tabular}{ccc}
\hline Parameter & $\begin{array}{c}\text { Linear motor } \\
\text { model }\end{array}$ & $\begin{array}{c}\text { Rotary motor } \\
\text { model }\end{array}$ \\
\hline Maximum $\left|\mathrm{X}_{\mathrm{p}}\right|$ & $0.1 \mathrm{~m}$ & $6 \mathrm{rads}$ \\
$\mathrm{M}_{\mathrm{bp}}$ & $0.5 \mathrm{~kg}$ & 0.2 \\
$\mathrm{M}_{\mathrm{b}}$ & $4 \mathrm{~kg}$ & $0.0091 \mathrm{Nm}^{2}$ \\
$\mathrm{M}_{\mathrm{p}}$ & $1 \mathrm{~kg}$ & $0.0091 \mathrm{Nm}^{2}$ \\
$\mathrm{G}$ & 100 & 100 \\
$\mathrm{~K}_{\mathrm{fp}}$ & $24 \mathrm{~N} / \mathrm{A}$ & $0.135 \mathrm{Nm} / \mathrm{A}$ \\
$\mathrm{K}_{\mathrm{fb}}$ & $47 \mathrm{~N} / \mathrm{A}$ & $0.134 \mathrm{Nm} / \mathrm{A}$ \\
$\mathrm{K}_{\mathrm{s}}$ & $10 \mathrm{~N} / \mathrm{m}$ & $0.05 \mathrm{~N} / \mathrm{rad}$ \\
$\mathrm{C}_{\mathrm{s}}$ & $3.4 \mathrm{~N} / \mathrm{m}^{2}$ & 0 \\
$\mathrm{~K}_{\mathrm{boost}}$ & 5 & 3 \\
$\mathrm{~A}_{\mathrm{ratio}}$ & 2 & 2 \\
$\mathrm{~K}_{\mathrm{pb}}$ & 89.19 & 1.2 \\
$\mathrm{~K}_{\mathrm{ib}}$ & 0 & 0.0 \\
$\mathrm{~K}_{\mathrm{Db}}$ & 38.66 & 0.001 \\
\hline
\end{tabular}




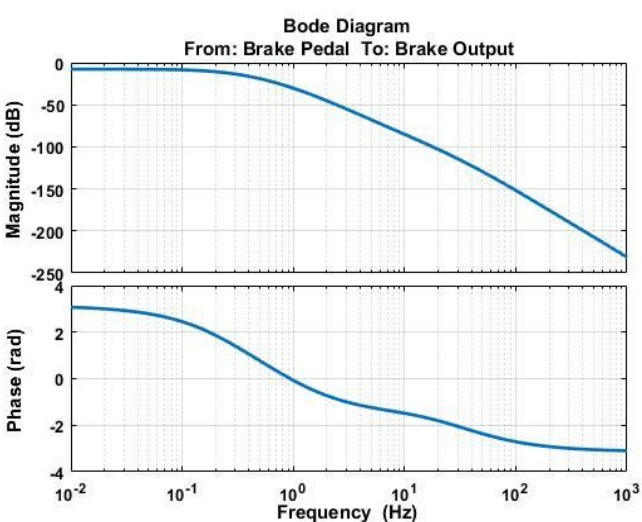

(a)

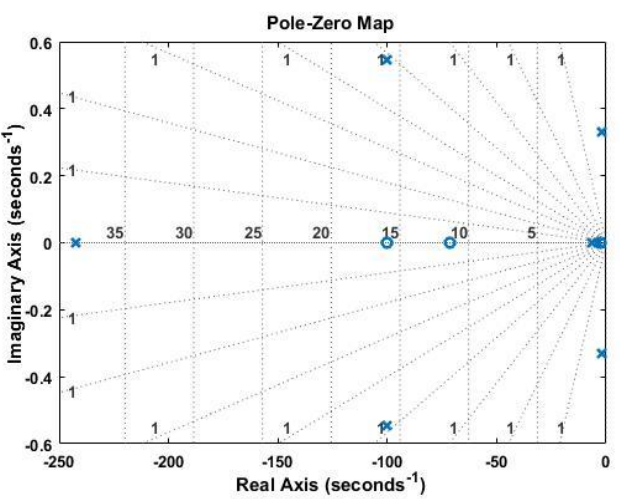

(b)

Figure 5. System stability, (a) frequency response, (b) pole-zero plot

The proposed model is simulated in the time domain for step, ramp, and random forces. A simulation was carried out to observe the brake and pedal motors' force and position for a step pedal force, as shown in Figure 6 (a). The results indicate the force amplification from the pedal motor to the brake motor with a scaling of around a ratio of 5 . In addition, the pedal motor and the brake actuator motor's position replication with the scaling factor of 2 . Due to the system's natural movement and damping, the physical delay is caused by pedal and pad movement. The pedal motor movement is controlled in the step force application by the brake feedback effect and the spring effect, as discussed in the controller model. The brake actuators follow the scaled step force application without any oscillations or vibrations in the system even under the pedal spring damper feedback. The proposed controller response is shown in Figure 6 (b) for increasing brake application. The ramp force amplification also suggests the brake controller capability of force amplification. In addition, the motor shows no vibrations under brake motor saturation and provide a feedback and retraction force to the driver. The proposed brake by wire model is then tested using a random force application with sudden force variations shown in Figure 6 (c). The proposed system amplifies the random pedal forces and provides the brake feedback with a spring effect to the pedal. In addition, the virtual spring allows automatic pedal retraction under the removal of the pedal force. Furthermore, the results show that the motor follows the scaled brake motor position correctly under brake application and brake retraction.

The results of Simulink tests show the amplification of pedal intention, position scaling, and virtual spring-based force feedback of the proposed controller. The system applicability was then tested using a bilateral teleoperation system. The bilateral controller consists of two DC rotary motors. The two motors act as the brake motor and the pedal motor. The regional scalers allow quick movement of brake pads before the initial brake application as it reduces the reactive force on the human foot under the non-contact moment. This technique compensates for the wear that could occur in the brake clamps. The nonlinear coefficient provides faster brake operation under non-contact clamp movement, and the pedal to brake motor scaling coefficient changes with respect to the brake force application. The experimental controller is also tested for a step force and multiple brake applications and retractions. The step force and position responses are shown in Figure 7 (a). Results provide a setting time of less than 100ms. The result is acceptable for the bilateral operation and could be tuned depending on the requirement. In addition, the brake motor amplifies the pedal force by three times, as shown in Figure 7 (a).

The experimental results show the position scaling according to the brake motor position. The driver feels the brake forces by the effects of virtual spring and damper and the force feedback where the damper reduces the oscillations caused by the virtual spring. The experimental results were gathered by applying and retracting the pedal three times, as shown in Figure 7 (b). The experimental results show that the brake pedal follows the brake caliper position. In addition, it shows the brake force amplification of the system under brake application. Finally, the brake retraction shows that virtual spring and damper effectively provide the brake feedback to the pedal motor and correctly retract the motor under pedal retraction. Therefore, the simulation and experimental results solidify the brake force amplification, position scaling, and force feedback capabilities of the proposed brake by wire system. 


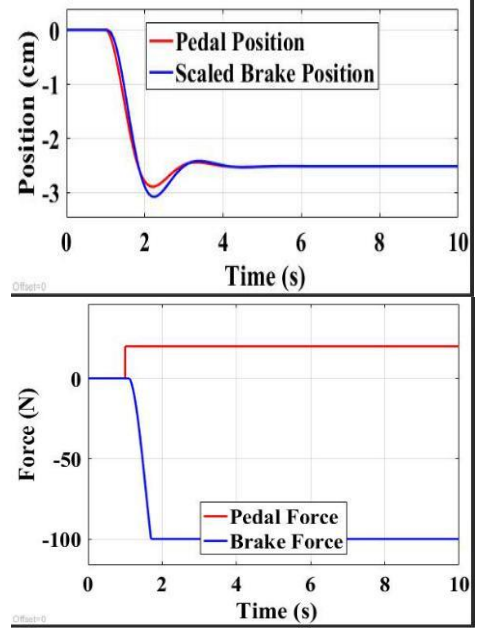

(a)
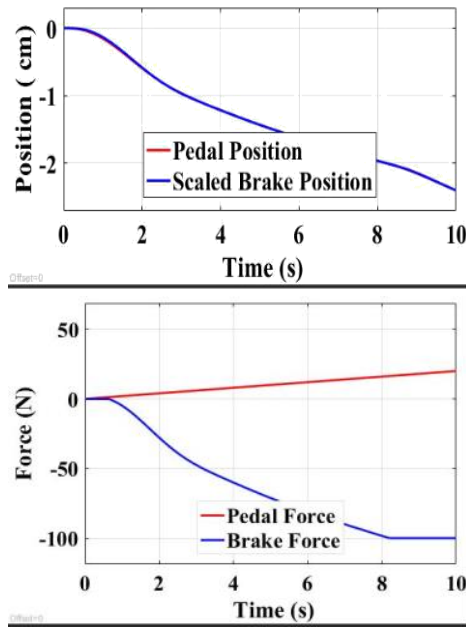

(b)
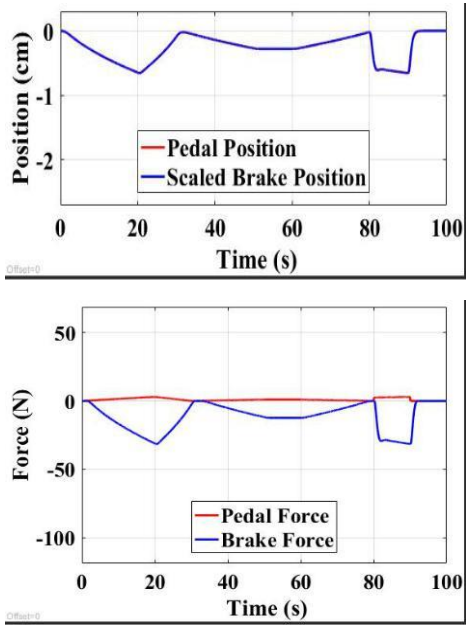

(c)

Figure 6. Simulation system time response of force and position, (a) Step response, (b) ramp response, (c) multiple brake application

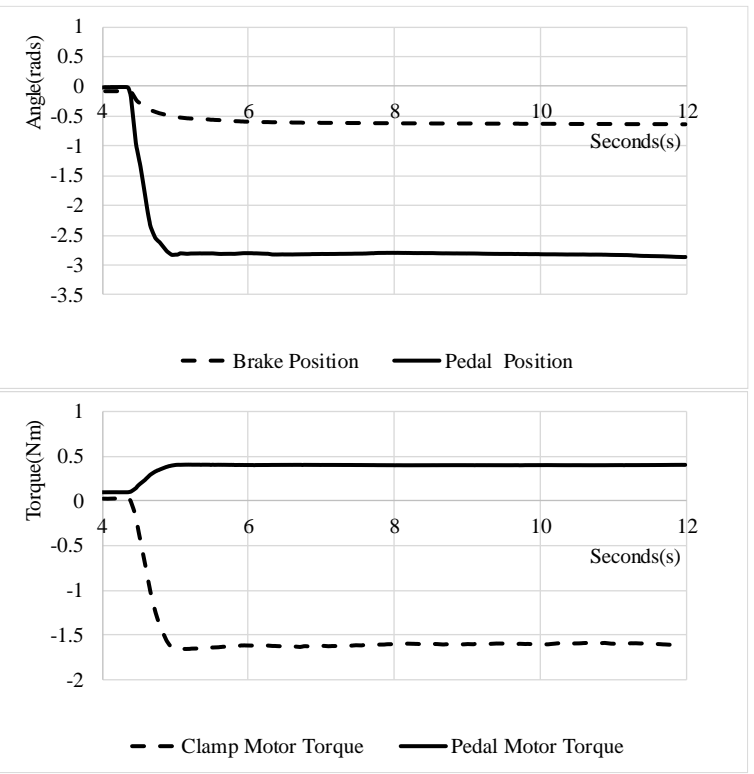

(a)

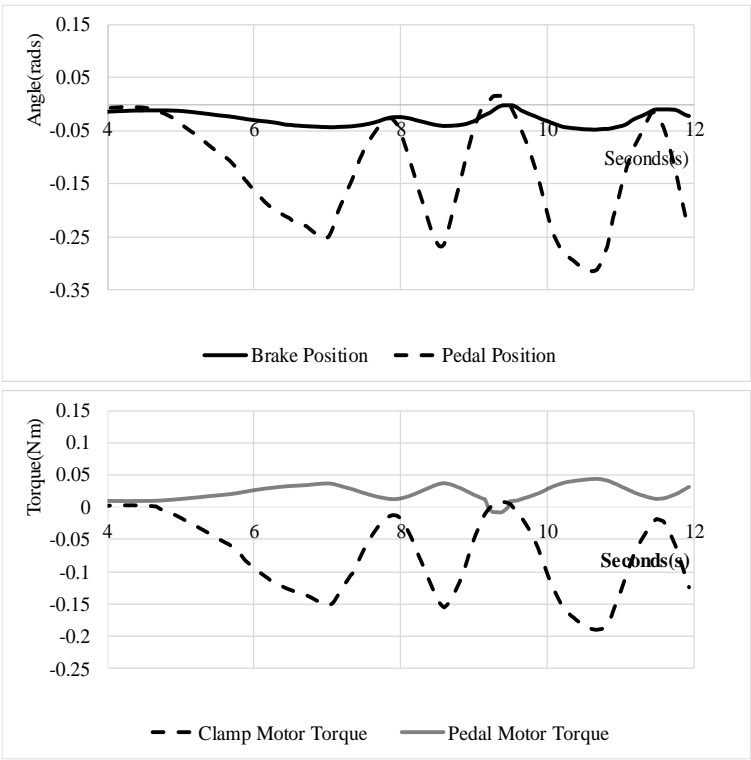

(b)

Figure 7. Experimental results of torque and position; (a) step application, (b) multiple brake application and retractions

\section{CONCLUSION}

The proposed system was simulated and tested in the experimental setup to observe the proposed controller performance and applicability. The novel controller's test results contain evidence of brake force amplification, pedal position scaling, and virtual spring-damper-based pedal retraction and force feedback capabilities of the proposed system. Simulation and experimental results provide evidence of the stability and performance required for a brake by wire system. Additionally, the proposed controller can be easily applied to conventional EMBs by adjusting the brake system's scaling coefficients allowing freedom in actuator selection. The DOB/RFOB based internal force measurement techniques only require motor current sensors and position sensors for real-world application, reducing EMI and noise effects. The above sensors are already available in current EMBs, allowing easy applicability for the proposed controller in current EMB systems. 


\section{ACKNOWLEDGEMENTS}

This research is supported by University of Moratuwa Senate Research Grant No: SRC/CAP/14/14.

\section{REFERENCES}

[1] I. Knight, A. Eaton and D. whitehead, "The reliability of electronically controlled systems on vehicles," TRL Limited, Crowthorne, United Kingdom, Rep. no. PR/SE/101/00, April 2001.

[2] Hai Wang et al., "Robust terminal sliding mode control for automotive electronic throttle with lumped un-certainty estimation," International Journal of Vehicle Design, vol. 74, no. 1, pp. 19-40, 2017, doi: 10.1504/IJVD.2017.084548.

[3] L. Ni, A. Gupta, P. Falcone and L. Johannesson, "Vehicle lateral motion con-trol with performance and safety guarantees," IFAC-PapersOnLine, vol. 49, no. 11, pp. 285-290, 2016, doi: 10.1016/j.ifacol.2016.08.043.

[4] S. Di Cairano, H. E. Tseng, D. Bernardini and A. Bemporad, "Vehicle Yaw Stability Control by Coordinated Active Front Steering and Differential Braking in the Tire Sideslip Angles Domain," in IEEE Transactions on Control Systems Technology, vol. 21, no. 4, pp. 1236-1248, July 2013, doi: 10.1109/TCST.2012.2198886.

[5] S. Mithun, S. Gayakwad, "Modeling and simulation of pneumatic brake system used in heavy commercial vehicle," IOSR Journal of Mechanical and Civil Engineering, vol. 11, no. 1, pp. 1-9, 2014.

[6] A. Arrif, "Design And Fabricate A Brake System And Mechanism," B.S. thesis, Faculty of Mechanical Engineering, Universiti Teknikal Malaysia Melaka, Melaka, 2012.

[7] E. Dinçmen, B. A. Güvenç and T. Acarman, "Extremum-Seeking Control of ABS Braking in Road Vehicles With Lateral Force Improvement," in IEEE Transactions on Control Systems Technology, vol. 22, no. 1, pp. 230-237, Jan. 2014, doi: 10.1109/TCST.2012.2229465.

[8] "Power brake," Encyclopedia Britannica. [Online]. Available: https://www.britannica.com/technology/power-brake (accessed Aug. 23, 2021).

[9] G. Mastinu and M. Ploechl, "Road and off-road vehicle system dynamics hand-book," Abingdon: CRC Press, 2014.

[10] Jiun-Jie Chen, Bo-Reui Chen and Shih-Chieh Huang, "The failure modes study for the electric vacuum brake booster system," 2012 12th International Conference on ITS Telecommunications, 2012, pp. 190-194, doi: 10.1109/ITST.2012.6425163.

[11] C. Gonzalez, Whats the di erence between pneumatic, hydraulic, and electrical actuators?, 2015. [Online]. Available: https://www.asme.org/engineering-topics/articles/renewable-energy/catching-the-sunhttp://www.machinedesign.com/linearmotion/ what-s-difference-between-pneumatic-hydraulic-and-electrical-actuators

[12] W. Xiang, P. C. Richardson, C. Zhao and S. Mohammad, "Automobile Brake-by-Wire Control System Design and Analysis," in IEEE Transactions on Vehicular Technology, vol. 57, no. 1, pp. 138-145, Jan. 2008, doi: 10.1109/TVT.2007.901895.

[13] L. Yu, L. Ma, J. Song and X. Liu, "Magnetorheological and Wedge Mechanism-Based Brake-by-Wire System With Self-Energizing and Self-Powered Capability by Brake Energy Harvesting," in IEEE/ASME Transactions on Mechatronics, vol. 21, no. 5, pp. 2568-2580, Oct. 2016, doi: 10.1109/TMECH.2015.2512579.

[14] K. Rajashekara, "Parallel between More Electric Aircraft and ElectricVHybrid Vehicle Power Conversion Technologies," in IEEE Electrification Magazine, vol. 2, no. 2, pp. 50-60, June 2014, doi: 10.1109/MELE.2014.2312460.

[15] G. Park, S. Choi and D. Hyun, "Clamping force estimation based on hysteresis modeling for electromechanical brakes," International Journal of Automotive Technology, vol. 18, no. 5, pp. 883-890, 2017, doi: 10.1007/s12239017-0086-5

[15] D. Iles-Klumpner, I. Serban and M. Risticevic, "Automotive Electrical Actuation Technologies," 2006 IEEE Vehicle Power and Propulsion Conference, 2006, pp. 1-6, doi: 10.1109/VPPC.2006.364364.

[17] R. Hoseinnezhad, A. Bab-Hadiashar and T. Rocco, "Real-Time Clamp Force Measurement in Electromechanical Brake Calipers," in IEEE Transactions on Vehicular Technology, vol. 57, no. 2, pp. 770-777, March 2008, doi: 10.1109/TVT.2007.906374.

[18] R. Hoseinnezhad, "Position sensing in brake-by-wire callipers using resolvers," in IEEE Transactions on Vehicular Technology, vol. 55, no. 3, pp. 924-932, May 2006, doi: 10.1109/TVT.2006.874576.

[19] H. Sakai, D. Tomizuka and K. Ohnishi, "A method of scaling bilateral control system with time delay in terms of modal space," 2016 IEEE International Conference on Industrial Technology (ICIT), 2016, pp. 24-29, doi: 10.1109/ICIT.2016.7474720.

[20] K. Tsuda, S. Sakaino and T. Tsuji, "Bilateral control between electric and electro-hydrostatic actuators using feedback modulator," IECON 2016 - 42nd Annual Conference of the IEEE Industrial Electronics Society, 2016, pp. 506-511, doi: 10.1109/IECON.2016.7793504.

[21] A. Abou El Kalam, A. Ferreira and F. Kratz, "Bilateral Teleoperation System Using QoS and Secure Communication Networks for Telemedicine Applications," in IEEE Systems Journal, vol. 10, no. 2, pp. 709-720, June 2016, doi: 10.1109/JSYST.2015.2422992.

[22] V. Chawda and M. K. O'Malley, "Position Synchronization in Bilateral Teleoperation Under Time-Varying Communication Delays," in IEEE/ASME Transactions on Mechatronics, vol. 20, no. 1, pp. 245-253, Feb. 2015, doi: 10.1109/TMECH.2014.2317946. 
[23] A. M. H. S. Abeykoon and K. Ohnishi, "Implementation of pedal feeling for Brake By Wire system using bilateral control," 2008 IEEE International Symposium on Industrial Electronics, 2008, pp. 1347-1352, doi: 10.1109/ISIE.2008.4677132.

[24] S. Saric, A. Bab-Hadiashar and R. Hoseinnezhad, "Clamp-Force Estimation for a Brake-by-Wire System: A Sensor-Fusion Approach," in IEEE Transactions on Vehicular Technology, vol. 57, no. 2, pp. 778-786, March 2008, doi: 10.1109/TVT.2007.905251.

[25] X. Gong, W. Ge, J. Yan, Y. Zhang and X. Gongye, "Review on the Development, Control Method and Application Prospect of Brake-by-Wire Actuator," Actuators, vol. 9, no. 1, pp. 1-24, 2020, doi: 10.3390/act9010015.

[26] X. Gong, L. Qian, W. Ge and L. Wang, "Research on the Anti-Disturbance Control Method of Brake-by-Wire Unit for Electric Vehicles," World Electr. Veh. J., vol. 10, no. 2, pp. 1-16, 2019, doi: /10.3390/wevj10020044.

[27] S. K. Baek, H. K. Oh, J. H. Park, Y. J. Shin and S. W. Kin, "Evaluation of Efficient Operation for Electromechanical Brake Using Maximum Torque per Ampere Control," Energies, vol. 12, no. 10, pp. 1-13, 2019, doi: 10.3390/en12101869.

[28] W. Han, L. Xiong and Z. Yu, "Interconnected Pressure Estimation and Double Closed-Loop Cascade Control for an Integrated Electrohydraulic Brake System," in IEEE/ASME Transactions on Mechatronics, vol. 25, no. 5, pp. 2460-2471, Oct. 2020, doi: 10.1109/TMECH.2020.2978534.

[29] Qian L and Zhao X. Observer-based friction force estimation for brake system under low-frequency vibration. Journal of Vibration and Control, March 2021, doi:10.1177/10775463211000496

[30] A. M. H. S. Abeykoon and Kouhei Ohnishi, "Virtual tool for bilaterally controlled forceps robot-for minimally invasive surgery," The International Journal of Medical Robotics and Computer Assisted Surgery, vol. 3, no. 3, pp. 271-280, 2007, doi: 10.1002/rcs.147.

[31] E. Sariyildiz and K. Ohnishi, "An Adaptive Reaction Force Observer Design," in IEEE/ASME Transactions on Mechatronics, vol. 20, no. 2, pp. 750-760, April 2015, doi: 10.1109/TMECH.2014.2321014

[32] A. Suzuki and K. Ohnishi, "Frequency-Domain Damping Design for Time-Delayed Bilateral Teleoperation System Based on Modal Space Analysis," in IEEE Transactions on Industrial Electronics, vol. 60, no. 1, pp. 177-190, Jan. 2013, doi: 10.1109/TIE.2012.2183832.

[33] E. Sariyildiz and K. Ohnishi, "Stability and Robustness of Disturbance-Observer-Based Motion Control Systems," in IEEE Transactions on Industrial Electronics, vol. 62, no. 1, pp. 414-422, Jan. 2015, doi: 10.1109/TIE.2014.2327009.

[34] E. Sariyildiz and K. Ohnishi, "On the Explicit Robust Force Control via Disturbance Observer," in IEEE Transactions on Industrial Electronics, vol. 62, no. 3, pp. 1581-1589, March 2015, doi: 10.1109/TIE.2014.2361611.

[35] The mathworks, Inc., Natick, MA 5, 1998.

\section{BIOGRAPHIES OF AUTHORS}

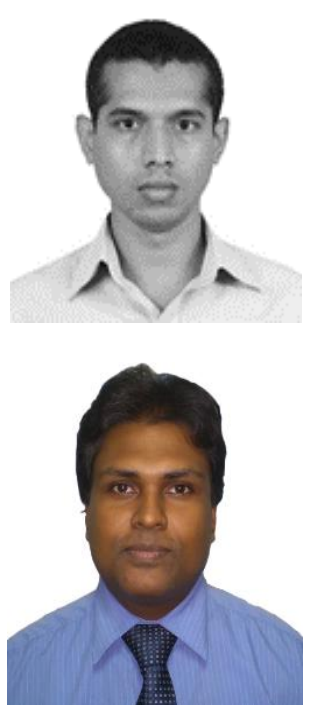

W. A. Shanaka P. Abeysiriwardhana received his B.Sc. (Hons) and M.Sc. degree in Electrical Engineering from the University of Moratuwa, Sri Lanka in 2014 and 2015, respectively. He is currently pursuing his Ph.D. degree in Hiroaki Nishi Laboratory, Keio University, Japan. He is a recipient of the Japanese Government Monbukagakusho (MEXT) Scholarship. His research interests include intelligent control, network function virtualization and smart community infrastructure.

A. M. Harsha S. Abeykoon received the B.Sc. degree in Electrical Engineering from University of Moratuwa, Sri Lanka in 2002. He received his M.Sc and PhD in Robotics and Control from the Keio University, Japan in 2005 and 2008 respectively. From 2009 onwards he has been working in the University of Moratuwa Department of Electrical Engineering as a Senior Lecturer. He has served the Asian Institute of Technology (Thailand) as an Assistant Professor during his sabbatical leave period. His research interests include motion control, mobile robotics and bilateral control related to biomedical engineering. Dr. Harsha is Senior member of IEEE and IES. He has worked as the secretary of the IEEE Sri Lanka section. He has been the general chain of ICIAfS 2014 conference. 